\title{
Perfusão pulmonar anterógrada "versus" retrógrada na preservação pulmonar para transplante em modelo canino de viabilidade pulmonar pós-morte*
}

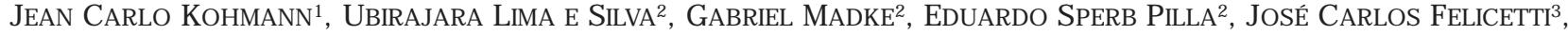 \\ José de Jesus Peixoto Camargo ${ }^{4}$, Paulo IVo Homem de Bittencourt ${ }^{5}$, Paulo Francisco Guerreiro Cardoso ${ }^{6}$
}

\begin{abstract}
A doação pulmonar após parada cardiocirculatória tem sido estudada experimentalmente na obtenção de órgãos para transplante, porém a severa lesão isquêmica/ reperfusão exigem métodos de preservação que permitam viabilidade pulmonar. A perfusão do enxerto com solução cristalóide hipotérmica via anterógrada (artéria pulmonar) é o método de preservação mais utilizado, porém esta via não perfunde a circulação brônquica, permitindo a retenção sanguínea neste território capaz de desencadear fenômenos de lesão de reperfusão. Isto nos levou a testar os efeitos da perfusão anterógrada versus retrógrada (via átrio esquerdo, capaz de perfundir a circulação brônquica) em modelo canino de transplante unilateral cujos pulmões foram extraídos 3 horas após parada cardiorrespiratória. Doze cães doadores foram sacrificados com tiopental sódico e mantidos à temperatura ambiente sob ventilação mecânica durante 3 horas, após as quais os animais foram randomizados e os blocos cardiopulmonares perfundidos via retrógrada $(n=6)$ ou anterógrada $(n=6)$ com solução de Euro-Collins modificada e extraídos. Os receptores $(n=12)$ foram anestesiados, pneumonectomizados e submetidos a transplante pulmonar esquerdo recebendo enxertos perfundidos por via retrógrada (grupo I) ou anterógrada (grupo II). A pós a reperfusão do enxerto, os animais foram

mantidos sob ventilação mecânica $\left(\mathrm{FiO}_{2}=1\right.$ ) por 6 horas, sendo então sacrificados. Durante este período obtiveram-se medidas hemodinâmicas e gasometrias arteriais, além de amostras de tecido pulmonar para dosagem de ATP intracelular. As medidas hemodinâmicas não diferiram entre os grupos. Nos animais do grupo I a $\mathrm{PaO}_{2}$ e $\mathrm{PaCO}_{2}$ foram superiores às do grupo II ( $p=0,016$ e $p=0,008$, respectivamente). 0 ATP intracelular não diferiu entre os grupos, embora tenha se reduzido nas amostras obtidas na extração do enxerto do doador quando comparados aos valores após a reperfusão $(p=0,01)$ e ao término do período de avaliação $(p=0,01)$. Os autores concluem que, neste modelo experimental, a perfusão retrógrada hipotérmica resulta em função superior do enxerto após 3 horas de isquemia normotérmica sob ventilação mecânica. ( Pneumol 1999;25(2):78-83)
\end{abstract}

\section{Antegrade versus retrograde lung perfusion in pulmonary preservation for transplantation in a canine model of post-mortem lung viability}

Lung retrieval following cardio-circulatory arrest has been studied experimentally, however severe ischemia/reperfusion injury requires improved methods of graft preservation. Allograft perfusion with crystalloid solution delivered via pulmonary artery (antegrade perfusion) remains the standard procedure, however it does not provide adequate washout of the blood retained within the bronchial circulation which may trigger reperfusion injury.

This has led the authors to test the impact of antegrade versus retrograde (via left atrium) perfusion of lung grafts submitted to 3 hours of warm ischemia after cardio-circulatory arrest in a dog model of left lung allotransplantation. Twelve donor dogs were sacrificed with thiopental sodium and kept under mechanical ventilation at room temperature for 3 hours. They were randomized and the heart-lung blocks harvested after being perfused in a retrograde (group I, $n=6$ ) or antegrade (group II, $n=6$ ) fashion with modified Euro-Collins solution. Twelve recipient animals were submitted to a left lung transplant receiving the grafts from both groups and the assessment was performed during 6 hours. Hemodynamic parameters were similar for animals in both groups. The gas exchange (arterial $\mathrm{PaO}_{2}$ and $\mathrm{PaCO}_{2}$ ) in recipients of group I (retrograde perfusion) was significantly better when compared to recipients of grafts perfused via pulmonary artery. Intracellular ATP did not show difference between the groups, however there was a measurable drop in its values when samples obtained upon extraction were compared to those measured after reperfusion and at the end of the assessment. The authors concluded that retrograde perfusion yields better pulmonary function after 6 hours of reperfusion in this animal model of left lung allotransplantation following 3 hours of normothermic ischemia under mechanical ventilation.

* Trabalho realizado, com recursos do CNPq e FAPERGS, no Departamento de Cirurgia Torácica, Pavilhão Pereira Filho, Santa Casa de Misericórdia de Porto Alegre, Fundação Faculdade Federal de Ciências Médicas de Porto Alegre e Departamento de Fisiologia, Instituto de Ciências Básicas da Saúde, Universidade Federal do Rio Grande do Sul.

1. (In memoriam) Cirurgião do Dep.de Cirurgia Torácica do Pavilhão Pereira Filho, Santa Casa de Porto Alegre.

2. Estudante de Medicina da Fundação Faculdade Federal de Ciências Médicas de Porto A legre.

3. Professor Assistente de Cirurgia Torácica, Dep.de Cirurgia, Fundação Faculdade Federal de Ciências M édicas de Porto Alegre. Cirurgião Torácico do Pavilhão Pereira Filho, Santa Casa de Porto Alegre.

4. Professor Adjunto de Cirurgia Torácica, Dep.de Cirurgia, Fundação Faculdade Federal de Ciências M édicas de Porto Alegre. Chefe do Dep. de Cirurgia Torácica do Pavilhão Pereira Filho, Santa Casa de Porto Alegre.

5. Professor Adjunto, Dep.de Fisiologia Cardiovascular, Instituto de Ciências Básicas da Saúde, U niversidade Federal do Rio Grande do Sul.

6. Professor Adjunto de Cirurgia Torácica, Dept.de Cirurgia, Fundação Faculdade Federal de Ciências Médicas de Porto A legre. Cirurgião Torácico do Pavilhão Pereira Filho, Santa Casa de Porto Alegre.

Endereço para correspondência - Paulo F. Guerreiro Cardoso, PaviIhão Pereira Filho, Santa Casa, Rua Prof. Annes Dias, 285, 10 andar - 90020-090 - Porto Alegre, RS. Telefax (051) 227-3909, 228-2510, e-mail: cardoso@santacasa.tche.br

Recebido para publicação em 14/12/98. Reapresentado em 10/3/99. A provado, após revisão, em 15/3/99. 
Descritores - Pulmão. Isquemia. Preservação pulmonar. Perfusão retrógrada. ATP.

Key words - Lung. Ischemia. Preservation. Retrograde perfusion. ATP.

\section{INTRODUÇÃO}

A reduzida oferta de doadores permanece como obstáculo principal ao desenvolvimento dos programas de transplante pulmonar. Fontes alternativas de obtenção de órgãos têm sido estudadas; dentre elas, a obtenção de pulmões de doadores após parada cardiocirculatória tem sido investigada experimentalmente por Egan et al.(1) $\mathrm{em}$ um modelo canino de transplante unilateral. Mais recentemente, U licny et al. ${ }^{(2)}$ utilizaram hiperventilação dos pulmões do doador, submetendo-os a períodos de até 4 horas de isquemia normotérmica, com resultados funcionais satisfatórios. A preservação pulmonar para transplante através da administração de soluções no ato da extração do enxerto é o método de eleição em uso clínico corrente. A perfusão pela artéria pulmonar (anterógrada) é a forma mais utilizada de administração de solução de preservação pulmonar, pois utiliza-se da via natural de perfusão, drenando-se a solução pelo átrio esquerdo. Entretanto, esta via de perfusão não elimina o sangue retido na circulação brônquica, além de necessitar de vasodilatadores da vasculatura pulmonar para que a perfusão seja uniforme e realizada sem elevação significativa da pressão hidrostática capilar pulmonar(3). A importância da circulação brônquica tem sido evidenciada como participante fundamental nos fenômenos da perfusão pulmonar ${ }^{(4)}$. A permanência de sangue e seus elementos figurados no interior da circulação brônquica favoreceria os fenômenos de lesão de reperfusão por ativação dos neutrófilos remanescentes neste leito vascular. A administração de solução preservadora no interior da circulação brônquica através da aorta foi proposta por

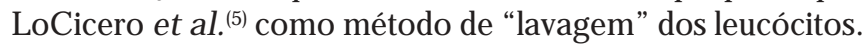
Em 1993, Sarsam et al ${ }^{(6)}$ descreveram um método simples de perfusão da solução preservadora através do átrio esquerdo, com drenagem pela artéria pulmonar (retrógrada) no ato da extração pulmonar, em dois pacientes, com bons resultados. Este método teria como vantagem teórica, a perfusão da circulação brônquica através das anastomoses naturais entre a circulação brônquica e pulmonar. Tal inferência é teórica, uma vez que a patência de tais comunicações é questionável e não passível de avaliação durante o momento da perfusão pulmonar com solução preservadora. No presente estudo, avaliamos a qualidade de preservação de pulmões extraídos três horas após a morte, comparando-se a perfusão com solução de Euro-Collins modificada administrada pela artéria pulmonar com drenagem pelo átrio esquerdo (anterógrada) versus retrógrada (átrio esquerdo com drenagem pela artéria pulmonar).
Siglas e abreviaturas utilizadas neste trabal ho

NADH - Forma reduzida da nicotinamida-adenina-dinucleotídeo 3PGA - 3-fosfoglicerato

$P G K$ - fosfoglicerato quinase

Cães doadores adultos ( $n=12$ ) pesando em média $12 \mathrm{~kg}$, após serem anticoagulados (heparina $5 \mathrm{mg} / \mathrm{kg} \mathrm{EV}$ ), foram sacrificados com uma dose letal de tiopental sódico $(65 \mathrm{mg} /$ $\mathrm{kg}$ ). A pós constatada a morte por parada cardiorrespiratória, foram intubados por via orotraqueal e ventilados mecânicamente $\left(\mathrm{FiO}_{2}=1,0, \mathrm{VC}=35 \mathrm{ml} / \mathrm{kg}, \mathrm{FR}=12\right.$ irpm $)$ em ventilador volumétrico Narcolog ( $\mathrm{N}$ arcosul Equipamentos Científicos Ltda., Porto A legre-RS) em temperatura ambiente durante 180 minutos. A pós este período, procedeu-se a uma esternotomia mediana, com exposição do tronco da artéria pulmonar e átrio esquerdo via intrapericárdica, bem como exposição da traquéia e veias cavas. Neste ponto, os animais foram randomizados em dois grupos: No grupo I (perfusão retrógrada, $\mathrm{n}=6$ ), os pulmões do doador foram perfundidos com solução de Euro-Collins $(50 \mathrm{ml} / \mathrm{kg})$ modificada a 4 으, administrada por canulação do átrio esquerdo, com drenagem por incisão no tronco da artéria pulmonar. No grupo II (perfusão anterógrada, $\mathrm{n}=6$ ), a perfusão foi realizada através de cânula instalada na artéria pulmonar, sendo a drenagem feita por atriotomia esquerda. A pressão de perfusão foi de $35 \mathrm{cmH}_{2} \mathrm{O}$, obtida por elevação do frasco de perfusão e, em ambos os grupos, durante a perfusão, os pulmões foram hiperinsuflados e a aorta descendente seccionada para evitar-se qualquer aumento de pressão hidrostática no átrio esquerdo durante a perfusão. Imediatamente após a perfusão, os pulmões foram extraídos em bloco com o coração, acondicionados imersos em solução fisiológica a 4 ํㅡ, até a dissecção do pulmão esquerdo e o seu reimplante no receptor. Não foram utilizados vasodilatadores pulmonares em ambos os grupos. Os animais receptores $(n=12)$ foram anestesiados com tiopental sódico (10 a $15 \mathrm{mg} / \mathrm{kg} \mathrm{EV}$ ), intubados e ventilados com uma mistura de $60 \% \mathrm{O}_{2}: 40 \% \mathrm{~N}_{2} \mathrm{O}$ (White-Martins Gases Medicinais S.A. - Porto A legre, RS), halotano $(0,5 \%$ a $1,5 \%)$, volume inspiratório de $30 \mathrm{ml} / \mathrm{kg}$, e freqüência respiratória ajustada para manter-se uma $\mathrm{PaCO}_{2}$ inferior a $40 \mathrm{mmHg}$. 0 receptor foi colocado em decúbito lateral direito, um cateter de Swan-Ganz posicionado na artéria pulmonar através da veia femoral e um cateter arterial instalado na artéria femoral direita. A través de uma toracotomia esquerda, o hilo pulmonar era preparado da maneira usual, a pneumonectomia esquerda realizada no receptor e 0 enxerto implantado, utilizando-se técnica previamente descrita ${ }^{(7,9,10)}$. Ao término das anastomoses, o pulmão esquerdo era reperfundido e a artéria pulmonar direita ligada 15 minutos após a reperfusão. A seguir, parâmetros hemodinâmicos 


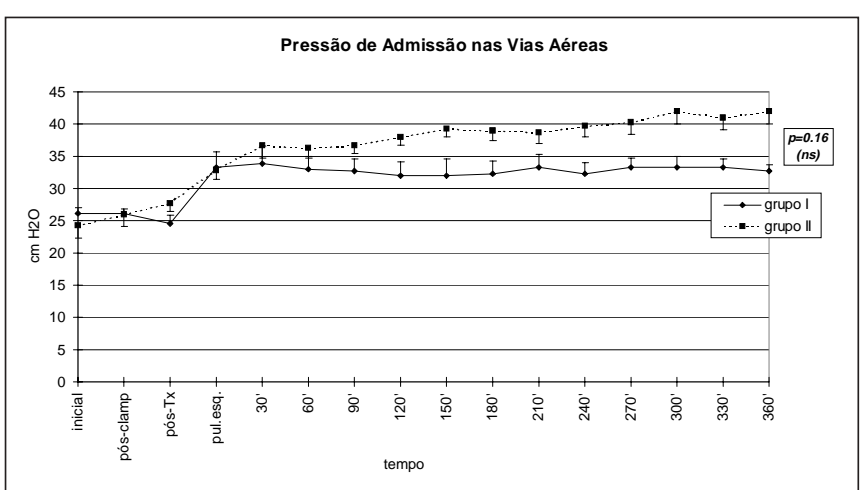

Figura 1 - Pressão de admissão nas vias aéreas inferior no grupo I (perfusão retrógrada)

(pressões arterial sistêmica, venosa central, da artéria pulmonar) foram obtidos e amostras de sangue arterial colhidas de 30 em 30 minutos durante 360 minutos, durante os quais 0 animal era ventilado com $\mathrm{FiO}_{2}=1,0$. A pós o período de avaliação citado, 0 animal era sacrificado com uma dose letal de cloreto de potássio. 0 pulmão transplantado era então ressecado e examinado, pesado e levado a uma estufa a $80^{\circ} \mathrm{C}$ por 36 horas, após as quais era pesado novamente para obtenção da relação peso úmido/ seco. Foram obtidas amostras de tecido pulmonar do enxerto no momento da extração pulmonar (após 3 horas de isquemia imediatamente após a perfusão com solução preservadora), após a reperfusão e no final da avaliação para análise de ATP intracelular. Estas amostras foram obtidas do lobo inferior esquerdo e imersas imediatamente em nitrogênio líquido, sendo conservadas em freezer a $-80^{\circ} \mathrm{C}$ até 0 seu processamento. A análise de ATP intracelular foi realizada utilizando-se um ATP KIT 366-UV (Sigma, USA ). A quantificação tecidual de trifosfato de adenosina foi obtida a partir de amostras homogeneizadas a $30.000 \mathrm{rpm}$ por 30 segundos num homogeneizador Polytron a $4 \stackrel{\circ}{\circ} \mathrm{C}$ em ácido tricloroacético a $6 \%(\mathrm{~m} / \mathrm{v})$, centrifugadas a 4 으 a $16.000 \mathrm{~g}$ por 10 minutos e os respectivos sobrenadantes foram analisados usando-se o kit supracitado. 0 método de detecção, baseado em Adams ${ }^{(11)}$, utilizou a monitoração espectrofométrica a $40 \mathrm{~nm}$ do consumo de NADH (forma reduzida da nicotinamida-adenina-dinucleotídeo), na presença da enzima gliceraldeído-fosfato desidrogenase (GADP), acoplado à fosforilação do 3-fosfoglicerato (3 PGA) pela fosfoglicerato quinase (PGK).O princípio da reação está descrito à seguir:

$$
\begin{aligned}
& \text { ATP (amostra) + 3PGA - } 2 \text { PGK } A D P+1,3 \text { diPGA } \\
& 1,3 \mathrm{diPGA}+\mathrm{NADH}-\mathrm{GAPD} \quad \ddot{\mathrm{a}} \mathrm{GA}-3 \mathrm{P}+\mathrm{NAD}++\mathrm{Pi}
\end{aligned}
$$

Todos os animais receberam tratamento humanitário de acordo com o "Guide for the Care and Use of Laboratory A nimals" preparado pela "National A cademy of Sciences" e

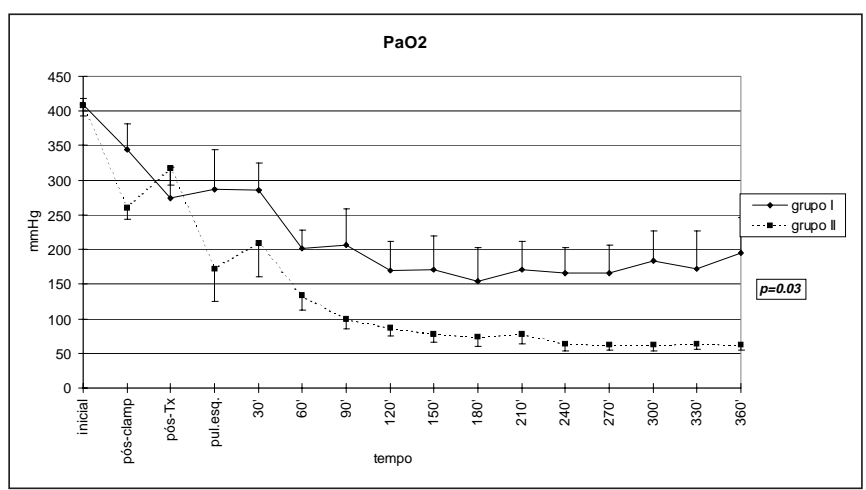

Figura 2 - $\mathrm{PaO}_{2}$ antes e após reperfusão do enxerto. Notar o desempenho superior do grupo I (perfusão retrógrada).

publicado pelo "National Institutes of Heath" (NIH número 80-23, 1978).

Os dados coletados foram armazenados em computador pessoal em planilha eletrônica. A análise estatística foi realizada por programa estatístico (Statmost, Data Most, Salt Lake City-USA), constando de testes comparativos das médias ( $t$ de Student) e análise de variância. Os resultados foram representados como média \pm desvio-padrão da média. 0 nível de significância estatística aceito para valores de $p$ inferiores a 0,05 .

\section{Resultados}

Não houve diferença significativa entre 0 peso dos animais utilizados (grupo I = 13,7 $\pm 2 \mathrm{~kg}$; grupo II $=11,5 \pm 2 \mathrm{~kg}$; $p=0,54)$. 0 tempo de isquemia normotérmica foi semeIhante nos 2 grupos ( 3 horas) e o tempo total para confecção das anastomoses vasculares e brônquica também não diferiu entre os grupos (grupo I = 41,1 minutos; grupo II = 40,6 minutos). Todos os animais sobreviveram ao período de avaliação de 6 horas após a reperfusão do enxerto. As medidas hemodinâmicas obtidas em ambos os grupos revelaram diferenças estatisticamente significativas nos valores da pressão arterial média (grupo I $=82,5 \pm 2 \mathrm{mmH}$ g; grupo $\|=74,9 \pm 2,1 \mathrm{mmH} \mathrm{g;} p=0,01)$. A pressão média na artéria pulmonar, embora algo superior no grupo de perfusão anterógrada, não atingiu diferença estatisticamente significativa (grupo I = 19,8 $\pm 1,2 \mathrm{mmH}$ g; grupo $\mathrm{II}=26,5 \pm$ $4,2 \mathrm{mmH} \mathrm{g} ; p=0,13)$. A pressão de admissão nas vias aéreas foi significativamente menor no grupo I (figura $1 ; p=$ 0,005 ). Dentre os parâmetros de troca gasosa (gasometria arterial), a $\mathrm{PaO}_{2}$ no grupo I revelou melhor performance dos pulmões submetidos a perfusão retrógrada $(p=0,016$; figura 2), o mesmo ocorrendo com a $\mathrm{PaCO}_{2}$ ( $\mathrm{p}=0,008$; figura 3). A relação peso úmido/ seco foi maior no grupo de perfusão anterógrada, indicando um aumento significativo de acúmulo de água intrapulmonar (edema) nestes pulmões (figura 


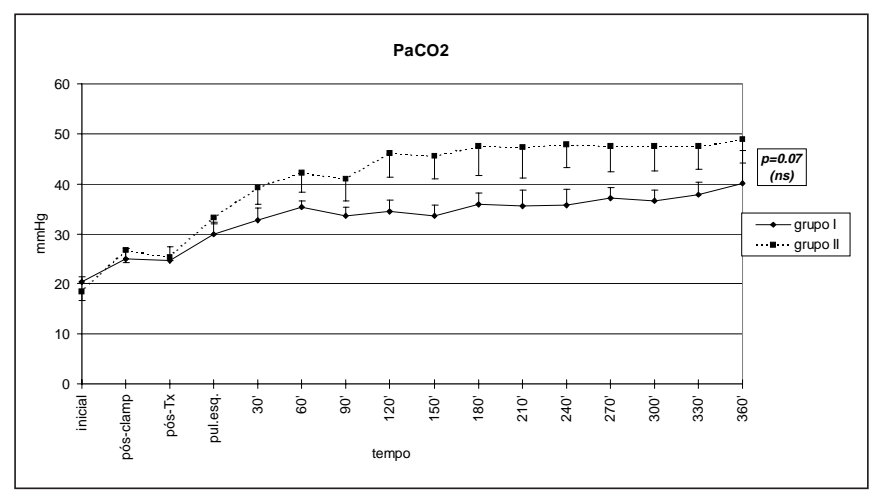

Figura $3-\mathrm{PaCO}_{2}$ em ambos os grupos antes e após transplante demonstrando valores menores no grupo I (perfusão retrógrada)

$4 ; p=0,025)$. 0 ATP intracelular não revelou diferenças estatisticamente significativas entre os grupos; entretanto, houve decréscimo significativo de seus valores entre as amostras realizadas obtidas na extração do enxerto do doador, quando comparados aos valores após a reperfusão $(p=0,01)$ e ao término do período de avaliação $(p=0,01)$, respectivamente (figura 5).

\section{DISCUSSÃO}

A utilização de doadores após a morte clínica (parada cardiocirculatória) tem sido estudada como fonte alternativa para doação de órgãos; entretanto, a questão da viabilidade pulmonar após a morte permanece em aberto. Kayano et al. ${ }^{(12)}$ demonstraram experimentalmente que pulmões submetidos a 3 horas de isquemia normotérmica podem ser viáveis para o transplante. 0 impacto positivo da hiperventilação na preservação de aloenxertos já foi demonstrado experimentalmente ${ }^{(13)}$, o que justifica seu uso clínico corrente nos programas de transplante pulmonar. Os mesmos efeitos benéficos foram observados em pulmões de ratos mantidos ventilados com oxigênio e extraídos até 4 horas após parada cardiocirculatória(14). 0 mesmo grupo demonstrou que a adição de solução de preservação ao modelo resultava em melhor performance funcional pulmonar após reperfusão(15). Entretanto, a transposição desta situação experimental para uma situação clínica deve ser feita com cautela e, obrigatoriamente, deverá passar antes pelo crivo de um modelo experimental de maior porte. Baseados neste princípio, adaptamos um modelo canino de transplante pulmonar unilateral esquerdo desenvolvido há mais de 10 anos $^{(9)}$, adicionando apenas a parada cardiorrespiratória e isquemia normotérmica por tempos diferentes até atingirmos o limite de viabilidade, que nesta preparação foi de 3 horas, que confirmou as conclusões de Kayano ${ }^{(12)}$ previamente descritas. Dada a injúria isquêmica severa imposta aos pulmões, utilizamo-nos de técnicas de preservação consideradas ideais. Para isto empregamos ven-

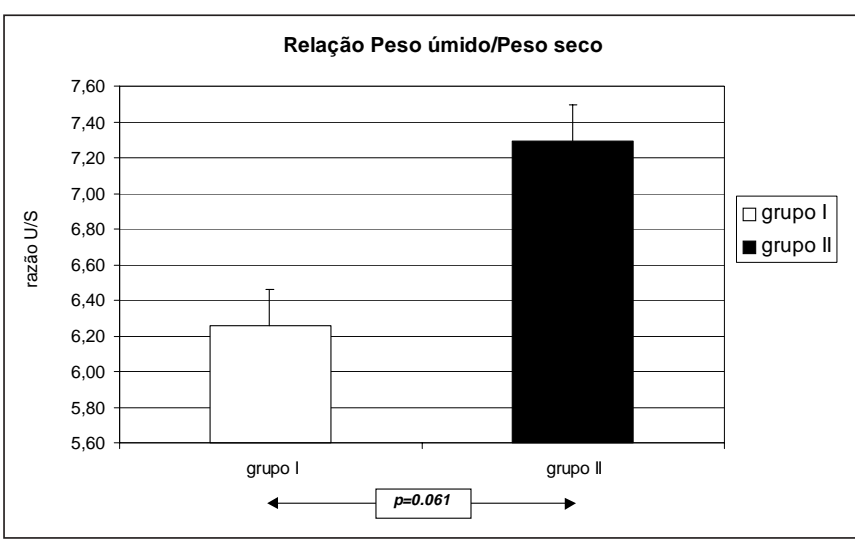

Figura 4 - Relação peso úmido/seco entre os grupos após 6 horas de reperfusão do enxerto. Notar diferença significativa entre os grupos no acúmulo de água intrapulmonar.

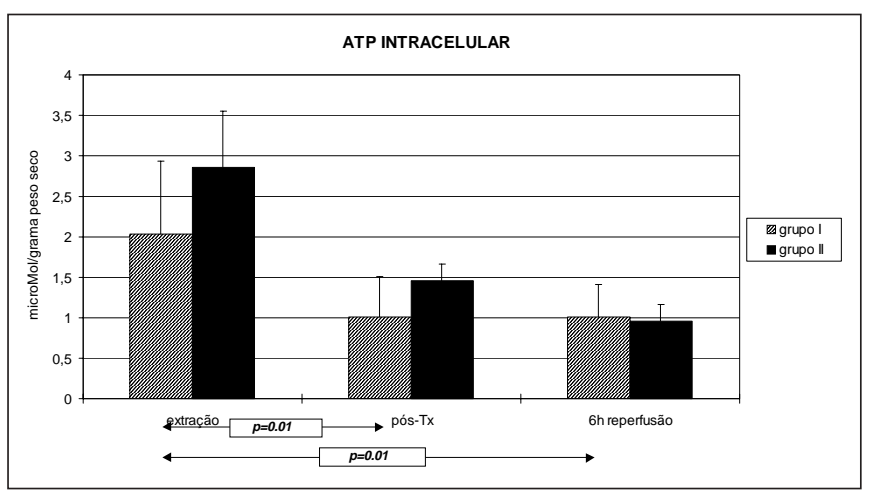

Figura 5 - Medida de ATP intracelular. Notar a ausência de diferença significativa entre os grupos e decréscimo progressivo das reservas de energia intracelular até o fim do período da reperfusão (360 minutos).

tilação mecânica durante o perío do isquêmico e hiperinsuflação durante a extração(13), perfusão com solução preservadora usualmente utilizada clinicamente. Demonstramos anteriormente que a adição de prostaglandinas ao modelo não resultava em melhora considerável da qualidade de preservação bem como a performance do enxerto até 6 horas após a reperfusão ${ }^{(7)}$, provavelmente devido à presença de algum outro fator que manteria a lesão de reperfusão. Conjecturamos portanto que, uma vez que a injúria isquêmica nesta situação aparentemente já seria máxima, a amplificação da lesão de reperfusão poderia estar relacionada à presença de elementos figurados do sangue remanescentes na circulação brônquica ativando a produção de radicais livres e, por conseguinte, interferindo negativamente na viabilidade destes pulmões. Estudos de outros autores confirmaram a melhora da função do enxerto, seja pela perfusão da circulação brônquica em conjunto com a perfusão anterógrada(5), ou por via retrógrada através do átrio esquerdo(6). Esta "lavagem" da circulação brônquica pelas anastomoses entre a circulação 
brônquica e pulmonar ao nível da circulação venosa pulmonar promove melhor distribuição da solução através da circulação pulmonar, até mesmo dispensando o uso de vasodilatadores como pré-requisito básico para obter-se uma boa perfusão quando se utilizam soluções com alto teor de potássio. Isto se deve ao fato de este eletrólito causar intensa vasoconstrição pulmonar, prejudicando a perfusão da circulação pulmonar distal. Nossos resultados da avaliação funcional após reperfusão do enxerto demonstram que, mesmo utilizando solução com alto teor de potássio e na ausência de uma vasodilatador pulmonar, a perfusão retrógrada promove melhora significativa da performance destes pulmões submetidos a severa injúria isquêmica pós-morte. Recentemente, Chen et al. ${ }^{(14)}$ demonstraram que pulmões caninos perfundidos via retrógrada com solução de Euro-Collins e armazenados por 6 horas a $4 \stackrel{\circ}{ } \mathrm{C}$ possuiam função superior aos perfundidos por via anterógrada. Nossos achados estão de acordo com estes autores, uma vez que verificamos que o edema pulmonar é significativamente menor após o transplante e reperfusão no grupo que recebeu perfusão da solução preservadora por via retrógrada, como demonstrado pelas diferenças significativas na relação peso úmido/ seco. Varela et al. ${ }^{(15)}$ demonstraram experimentalmente em porcos que a perfusão de solução de preservação marcada com isótopo radioativo, quando administrada via retrógrada pelo átrio esquerdo, resultava em maior concentração do radiotraçador na árvore traqueobrônquica. 0 mesmo autor ${ }^{(16)}$ utilizou perfusão com solução preservadora (Euro-Collins modificada) por via retrógrada nos enxertos pulmonares em 21 transplantes clínicos e concluiu que função pulmonar pós-transplante era satisfatória, bem como a viabilidade das anastomoses brônquicas. A questão da patência das anastomoses entre a circulação brônquica e pulmonar durante e perfusão com solução preservadora permanece em aberto. Baretti et al. ${ }^{(17)}$, em estudo experimental sobre a distribuição da solução de preservação em pulmões de porcos, concluíram que a atelectasia interfere negativamente na distribuição da solução nos pulmões do doador no momento da extração e que os vasodilatadores pulmonares (prostaciclina) não causavam impacto benéfico significativo. Tais achados podem ser indicativos da oclusão das anastomoses durante a atelectasia, razão pela qual pulmões insuflados possuem qualidade de preservação superior, como demonstrado por Puskas et al. ${ }^{(13)}$.

Em nosso estudo, a análise da reserva energética intracelular medida indiretamente pela quantidade de ATP não revelou diferenças signficativas entre os grupos neste modelo, embora houvesse um decréscimo mensurável e significativo a partir da reperfusão do enxerto até 6 horas após o transplante. Este achado demonstra claramente os efeitos duradouros da lesão de reperfusão. Durante a isquemia o ATP é rapidamente degradado em purinas sob a forma de hipoxantina e xantina. A ativação da enzima xantina desidrogenase, a qual é degradada para xantina oxidase, atua sobre a xanti- na acumulada nos tecidos durante a isquemia que, na presença de oxigênio disponibilizado aos tecidos no momento da reperfusão, a transforma em ácido úrico produzindo radicais livres superóxido e peróxido de hidrogênio. Esta cascata termina quando, na presença de ferro iônico, produz-se o radical hidroxila, que causa peroxidação lipídica das membranas celulares, determinando severa injúria endotelial vascular. 0 resultado final é um súbito e progressivo aumento da permeabilidade capilar pulmonar, causando edema e hemorragia parenquimatosa que terminarão por prejudicar as trocas gasosas no enxerto. Tais eventos foram descritos detalhadamente em outro modelo experimental de lesão de reperfusão, no qual concluímos ser a quimiluminescência a melhor forma para sua quantificação ${ }^{(18)}$. A lesão de reperfusão parece estar intimamente ligada às reservas de energia celulares e vários méto dos de controle têm sido propostos. A utilização de captadores de radicais livres, como a dimetiltiouréia ${ }^{(19)}$, os inibidores da xantina oxidase (alopurinol)(20) $\mathrm{e}$ agentes quelantes de ferro (deferoxamina)(21) são algumas das inúmeras substâncias propostas para o seu controle. A constatação de que a ativação dos neutrófilos durante a isquemia é uma fonte de radicais livres no momento da reperfusão gerou outras alternativas, como a depleção de leucócitos antes do período de isquemia e durante a reperfusão, obtida pela filtragem destes elementos do sangue periférico(22). Entretanto, a maioria destas teses permanece ainda em investigação experimental e apenas algumas ganharam a arena clínica e não têm sido propostas como rotina. A nosso ver, no presente estudo, a explicação mais plausível para a redução pós-transplante da quantidade de DNA seria representada pela permanência dos fenômenos de lesão de reperfusão mesmo várias horas após a abertura dos clampes vasculares ao final do implante do enxerto. A despeito da aparente viabilidade do parênquima do ponto de vista funcional, a severa injúria causada pela isquemia normotérmica de 3 horas contribuiria para a manutenção da cascata da lesão de reperfusão, depletando progressivamente as reservas de energia intracelulares representadas pelo ATP. Especulações adicionais sobre o significado deste achado e sua projeção sobre tempo não poderão ser feitas pois estão além dos objetivos deste relato. A lém disso, uma vez que o desenho original do projeto não previa a mensuração de ATP, tendo sido incluído ao término dos experimentos, não dispomos de amostras dos pulmões do doador antes da parada cardiocirculatória para comparação e avaliação. Parece-nos, no entanto, que possa haver uma correlação entre a qualidade e viabilidade celular pós-isquêmica com as reservas de ATP intracelular.

Os resultados do presente estudo permitem-nos concluir que a perfusão hipotérmica retrógrada sem vasodilatador pulmonar resulta em melhor função do enxerto submetido a 3 horas de isquemia normotérmica sob ventilação e hiperóxia. Tais achados são, no entanto, preliminares e aguardam confirmação com índices fisiológicos de viabilidade pulmo- 
nar (e.g. dosagem dos produtos de peroxidação lipídica) em fase de conclusão. A aplicação prática futura desta técnica, apesar de ainda não se constituir em realidade clínica de uso corrente, pode ser uma perspectiva alentadora no que diz respeito ao uso de pulmões em pacientes sob ventilação mecânica após parada cardiocirculatória.

\section{Agradecimentos}

Os autores reconhecem e agradecem à Narcosul Equipamentos Científicos pelo fornecimento de equipamentos de anestesia utilizados nos experimentos e à Santa Casa de Misericórdia de Porto Alegre pela aquisição de equipamentos utilizados nos experimentos. Este trabalho é dedicado à memória de seu autor, por seu exemplo de dedicação e amizade que a todos nós inspirou.

\section{REFERÊNCIAS}

1. Egan T, Lambert J r C, Reddick R, et al. A strategy to increase the donor pool: Use of cadaver lungs for transplantation. Ann Thorac Surg 1991;52:1113-1121.

2. Ulicny J r K, Egan T, Lambert C, et al. Cadaver lung donors: effect of preharvest ventilation on graft function. Ann Thorac Surg 1993;55: 1185-1191.

3. Novick RJ , Reid KR, Denning L, Duplan J, Menkis AH, McKenzie FN. Prolonged preservation of canine lung allografts: the role of prostaglandins. Ann Thorac Surg 1991;51:853-859.

4. Deffebach ME, Charan NB, Lakshminarayan S, Buttler J. The bronchial circulation. Small but a vital attribute of the lung. Am Rev Resp Dis 1987;135:463-481.

5. LoCicero III J, Massad M, Matano J, Greene R, Dunn M, Michaelis LL. Contribution of the bronchial circulation to lung preservation. J Thorac Cardiovasc Surg 1991;101:807-814.

6. Sarsam MA, Yonan NA, Deiraniya AK, Rahman AN. Retrograde pulmonaryplegia for lung preservation in clinical transplantation: A new technique. J Heart Lung Transplant 1993;12:494-498.

7. Kohmann J C, Castro M, Silva U, Ruschel M, Madruga G, Felicetti J C, Camargo JJ P, Cardoso PFG. Efeito da prostaglandina E1 na viabilidade pulmonar de cadáver após transplante pulmonar unilateral em cães. Rev Col Bras Cir 1995;22:275-278.

8. Kohmann J C, Ruschel M, Madruga G, Castro M, Di Pietro D, Felicetti J C, Camargo JJ P, Cardoso PFG. Efeito da prostaglandina E1 na via- bilidade do pulmão de cadáver após transplante pulmonar unilateral em cães. J Pneumol 1994;20(Supl 3):145.

9. J ones MT, H sieh C, Yoshikawa K, Patterson GA, Cooper J D. A new model for assessment of lung preservation. J Thorac Cardiovasc Surg 1988;96:608-614.

10. Keshavjee SH, Yamazaki F, Cardoso PFG, McRitchie DI, Patterson GA, Cooper J D. A method of safe 12-hour pulmonary preservation. J Thorac Cardiovasc Surg 1989;98:529-534.

11. Adams $\mathrm{H}$. Adenosine $5^{\prime}$-triphosphate determination with phosphoglycerate kinase. In: Bergmeyer HU, ed. Methods of enzymatic analysis. New York: Academic Press, 1963.

12. Kayano K, Date H, Uno K, Shimizu N, Teramoto S. Evaluation of viability of the canine cadaver lung for transplantation. Acta M ed O kayama 1993;47:329-337.

13. Puskas J D, H irai T, Christie N, Mayer E, Slutsky A, Patterson GA. Reliable thirty-hour lung preservation by donor hyperinflation. J Thorac Cardiovasc Surg 1992;104:1075-1083.

14. Chen C, Gallagher RC, A rdery P, Dyckman W, Donahue S, Low HBC. Retrograde flush and cold storage for twenty-two to twenty-five hours lung preservation with and without prostaglandin E1. J Heart Lung Transplant 1997;16:658-666.

15. Varela A, Montero C, Cordoba M, et al. Improved distribution of pulmonary flush solution to the tracheobronchial wall in pulmonary transplantation. Eur Surg Res 1997;29:1-4.

16. Varela A, Montero C, Cordoba M, Serrano-Fiz S, Burgos R, Tellez J C, Tebar G, U garte J . Clinical experience with retrograde lung perfusion. Transplant Int 1996;9(Suppl 1P):S296-S298.

17. Baretti R, Bitu-Moreno J, Beyersdorf F, Matheis G, Francischetti I, Kreitmayr B. J Heart Lung Transplant 1995;14:80-91.

18. Castro MAA, Madruga GSP, Silva UL, Bock P, Klein AB, Felicetti J C, Camargo JJP, Cardoso PFG. Quantificação de produtos de peroxidação lipídica em modelo experimental de injúria de reperfusão pulmonar em ratos. J Pneumol 1996;22:65-68.

19. Detterbeck FC, Keagy BA, Paull DE, Wilcox BR. Oxygen free radical scavengers decrease reperfusion injury in lung transplantation. Ann Thorac Surg 1990;50:204-210.

20. Lynch MJ, Grum CM, Gallagher KP, Bolling SF, Deeb GM, Morganroth $M L$. Xantine oxidase inhibition attenuates ischemic-reperfusion lung injury. J Surg Res 1988;44:534-544.

21. Conte J V, Katz NM, Foegh ML, Wallace RB, Ramwell PW. Iron chelation therapy and lung transplantation. Effects of deferoxamine on lung preservation in canine single lung transplantation. J Thorac Cardiovasc Surg 1991;101:1024-1029.

22. Pillai R, Bando K, Schueller S, Zebley M, Reitz BA, Baumgartner WA. Leucocyte depletion results in excellent heart-lung function after 12 hours of storage. Ann Thorac Surg 1990;50:211-214. 